\title{
PRODUÇÃO CIENTIFICA: POR QUE MEDIR? O QUE MEDIR?
}

\section{Raimundo Nonato Macedo dos Santos}

\section{Resumo}

A ciência, quanto atividade, é uma construção social, complexa, que requer ousadia e altos investimentos. Não é neutra, nem extemporânea; graça na concentração do seu labor, o que, em conseqüência, favorece o monopólio econômico dos seus resultados. Elitiza-se, materializa-se no efeito São Mateus: a quem tem, mais lhe será dado. Portanto, boas intenções e contradições requerem reflexões, questionamentos, discussões, crítica e massa crítica, área de concentração da "Ciência das Ciências" contemplada neste trabalho.

Palavras-chave

Produção científica; Bibliometria; Cientometria; Ciência das ciências.

\section{SCIENTIFIC PRODUCTION: WHY TO MEASURE IT? WHAT TO MEASURE?}

\begin{abstract}
Science, how much activity, is a social, complex construction, that it requires courage and high investments. She is not neutral, nor extemporany; favor in the concentration of its work, what, in consequence, the monopoly economic of its results favors. Elitiza, it is materialized in the effect St. Mateus: to who it has, more it will be given to it. Therefore, good intentions and contradictions require reflections, questionings, quarrels, critical and critical mass, area of concentration of the? Science of Sciences? contemplated in this work.
\end{abstract}

\section{Keywords}

Cientific production; Bibliometry; Cientometry; Science of the science. 


\section{INTRODUÇÃO}

Nos últimos anos tem sido crescente o interesse de especialistas e autoridades governamentais por indicadores quantitativos que, além de auxiliar o entendimento da dinâmica de ciência e tecnologia (C\&T), funcionam também como instrumentos para o planejamento de políticas e tomada de decisões neste setor.

Depois da Segunda Guerra, os países cientificamente avançados deixaram a cargo de cientistas o poder de decisão no segmento de C\&T, confiando em sua visão e competência, comprovadas por sucessos em áreas estratégicas, principalmente na de energia nuclear. Contudo, o surgimento de novos desafios sócio-econômicos, - derivados, em grande parte, do enorme avanço científicotecnológico das últimas décadas - tornou tal modelo ineficaz.

Sua reestruturação exigiu a incorporação de políticos e burocratas que, por sua vez, passaram a demandar indicadores quantitativos que mostrassem claramente as tendências do setor de C\&T e as conseqüências das políticas implantadas.
Nesse cenário, o papel dos pesquisadores voltou a destacar-se, não só pela sua capacidade de equacionar problemas científicos e desenvolver soluções como de propor e validar tais indicadores, definindo seus alcances e limitações.

Surgiu então uma nova área, a "cienciometria" ou "cientometria", cuja meta é gerar informações e discussões que contribuam para a superação dos desafios característicos da ciência moderna.

A cientometria, tal qual se apresenta hoje, constitui-se fundamentalmente um reducionismo bibliométrico. Por sua vez, as premissas conceituais da bibliometria remontam ao começo do século XIX. Desde então, os fundamentos, as técnicas, as aplicações dos métodos bibliométricos evoluíram sobremaneira graças a inúmeras pesquisas. Esta abundância de trabalhos e, sobretudo a variedade de objetivos buscados tornaram confusa a idéia do que se pode fazer com a bibliometria, a tal ponto que, mesmo entre os especialistas da área há dificuldade de chegarem a um acordo a respeito de noções cruciais como: a terminologia empregada (bibliometria, 
cientometria, infometria, tecnometria); definições dos limites de aplicação (biblioteconometria, avaliação da pesquisa, sociologia da ciência, avaliação macro-econômica, sociologia da inovação, inteligência competitiva, tratamento de linguagem natural) e, mais importante de tudo, sobre a evolução e o futuro profissional dos seus especialistas (ROSTAING, 1996).

Com base nesta premissa, este trabalho tem como objetivo apresentar, a compilação da literatura científica tratando da constituição e da própria evolução do arcabouço teórico da área.

\section{ASPECTOS CONTEXTUAIS E TERMINOLÓGICOS}

Para avaliar as potencialidades da base científica e tecnológica dos países, monitorar as oportunidades em diferentes áreas e identificar atividades e projetos mais promissores para o futuro, auxiliando as decisões estratégicas dos gestores da política científica e tecnológica, faz-se necessário a formulação, o desenvolvimento e a implementação de sistemas de informação científica e técnica para produzir indicadores, métodos e ferramentas afins.

\section{a) Os sistemas de informação científica e técnica para a produção de indicadores científicos}

No processo de análise das informações científicas e técnicas para a produção de indicadores, encontrar a fonte de dados primários, em suporte magnético, mais adequada às necessidades de produção dos indicadores é a parte mais difícil. Em geral, as fontes de dados primários, em suporte magnético, não foram construídas para a produção dos indicadores, havendo necessidade de reformatar os campos antes da importação dos dados, operação sempre complicada (QUONIAM, 1992).

Porém, o mais inusitado do contexto dos dados primários é que existem somente duas bases de dados, com cobertura global e completas dos seus assuntos, reconhecidamente estruturadas para análise de informação para a produção de indicadores, sem necessidade de grandes manipulações prévias nos dados: a Web of Science e a World Patent Index. A primeira especializada em informação 
científica e a segunda em informação técnica, no domínio das patentes1.

\section{O ACERVO CIENTÍFICO DO ISI}

Estima-se que circulem hoje, pelo mundo, cerca de um milhão de periódicos científicos. Menos de um por cento desse volume, aproximadamente 8.500, encontra-se indexado nos bancos de dados do Institute for Scientific Information (ISI), situado na Filadélfia, EUA. Os periódicos são indexados nessa base após rigorosa seleção, o que qualifica essa fonte de dados como uma das mais conceituadas do mundo.

São três as bases de dados existentes no ISI. A primeira e mais antiga (1961) é a Science Citation Index (SCI) multidisciplinar, que indexa mais de 5.700 dos principais periódicos referentes a 164 áreas do conhecimento (hard sciences). A base SCI online, cobrindo aproximadamente 2.100 periódicos a mais que suas versões impressa e em CDROM, permite acesso às referências

\footnotetext{
1 DIALOG BLUESHEETS from Dialog Coorporation. Disponível em http://library.dialog.com/bluesheets/>. Acesso em 15 de jun. 2001.
}

citadas nas publicações. A velocidade de atualização é impressionante: 17.750 novos artigos são incorporados por semana. A versão online contém mecanismos de busca para cerca de $70 \%$ desse total, disponibilizando integralmente os abstracts dos artigos. Exemplos de disciplinas incluídas na base: agricultura, neurociência, astronomia, bioquímica, biologia, biotecnologia, física, química, ciência da computação e matemática.

No campo das ciências sociais, o ISI oferece uma base semelhante, a Social Sciences Citation Index (SSCI), lançada em 1972. Ela indexa mais de 1.725 periódicos, que abrangem 50 áreas do conhecimento. Inclui, em média, 2.700 novos artigos por semana. Contém mecanismos de busca que disponibilizam abstracts para $60 \%$ desses trabalhos. Entre as disciplinas cobertas pela base figuram história, direito, sociologia, lingüística, psicologia, antropologia, ciência política, saúde pública e estudos urbanos.

A terceira base indexada no ISI é a Arts \& Humanities Citation Index (AHCI), surgida em 1978. Ela indexa 1.144 
periódicos da área de artes $\mathrm{e}$ humanidades e introduz semanalmente 2.250 novos artigos, em média.

A representatividade da base SCI para a produção internacional, especialmente em certos domínios (como Física e Biologia, por exemplo), é pouco contestada pela comunidade científica, por ser das mais completas e aprofundadas. $\mathrm{O}$ mesmo não ocorre com a base SSCI, composta por disciplinas sociais que, por sua natureza, são menos internacionalizadas. Muitas das mais conceituadas e "nobres" publicações da área (como as européias), cujos periódicos não têm o inglês como língua mãe, não são por ela indexadas. Isso faz com que o meio acadêmico encare a Social Sciences Citation Index com certa reserva, considerando baixa sua representatividade e recomendando sua utilização com cautela.

Mesmo em relação às hard sciences, argumenta-se que há certo viés do SCI em benefício dos periódicos e publicações em língua inglesa, e especificamente dos norte-americanos, que predominam amplamente na base, ficando a ciência européia, em geral, e a dos países em desenvolvimento, em particular, sub- representadas. Em algumas áreas científicas, especialmente aquelas que têm um caráter mais aplicado, como a agricultura e as profissões da saúde, essa distorção se vê acentuada.

\section{SCIELO, UMA BASE BRASILEIRA}

A Scientific Electronic Library Online (SciELO) é uma biblioteca virtual que disponibiliza periódicos científicos brasileiros relacionados a sete áreas: Ciências Agrícolas, Ciências Biológicas, Química, Engenharia, Geociências, Ciências da Saúde e Ciências Humanas.

Desenvolvido a partir de um projeto executado em parceria pela FAPESP e pelo Centro Latino-Americano e do Caribe de Informação em Ciências da Saúde (BIREME), o endereço www.scielo.br/scielo encontra-se em formação. Deverá ser ampliado para atender a uma política que visa aumentar radicalmente, no curto prazo, a visibilidade e a credibilidade nacional e internacional das publicações científicas da América Latina e do Caribe. A proposta é oferecer amplo acesso a coleções de periódicos como um todo, aos 
fascículos de cada título de periódico e aos textos completos dos artigos.

Em termos cronológicos, a coleção de cada título individual começa em 1997, para revistas em circulação, ou a partir do primeiro número, para revistas criadas após 1997. As contribuições podem ser escritas em inglês, português e espanhol. Quanto ao suporte material, os periódicos da coleção não deverão, necessariamente, ser publicados na forma impressa.

\section{b) Aspectos metodológicos e} ferramentas afins usadas no processo de produção de indicadores

Para não perder o essencial da informação, e para se assegurar da cobertura, a mais completa possível, do assunto analisado, faz-se uso, no processo de produção dos indicadores, de uma massa considerável de dados e / ou de informação (QUONIAM, 1992).

Face a essa situação, a questão que se impõe é para encontrar métodos e técnicas que permitam extrair sentido nessa massa de informação, sem, no entanto, ter que ler documento por documento, o que tornaria inviável o processo (ROUSEAU-HANS; THIL, 1997).

\section{A CIENTOMETRIA E SUAS RELAÇÕES COM A BIBLIOMETRIA}

Os termos "cientometria" e estudos quantitativos da ciência e da tecnologia poderiam ser considerados sinônimos. No entanto, para o mesmo significado, o termo "bibliometria" é também consagrado pela sua considerável interface nos estudos quantitativos ou cientométricos. Há ainda, o termo "tecnometria", por vezes utilizados para designar os estudos quantitativos da tecnologia (XAVIER, 1995).

Em 1962, a partir dos estudos estatísticos aplicados à mão de obra e à literatura científica, Price observou que essas práticas obedeciam a leis gerais, e que os métodos empíricos aplicados para apurar periódicos e artigos, na determinação dos indicadores científicos, produziam coerência teórica, com representações de curvas estáveis e regulares (PRICE, 1963).

Em 1969, Pritchard definia a bibliometria como: "a aplicação de métodos matemáticos e estatísticos a livros, artigos 
e outras mídias de comunicação", (PRICTCHARD, 1969).

Neste mesmo ano, Price definiu a cientometria como: "as pesquisas quantitativas de todas as coisas que dizem respeito à ciência e, aos quais podem ser atribuídos números" (PRICE, 1969). Esta definição tão ampla da cientometria, interpretada segundo o material publicado na revista Scientometrics2, ou seja, "estudos de avaliação de publicações (periódicos, artigos, patentes) de autores, de citação", evidencia que, do ponto de vista da prática, a cientometria restringese a aplicações bibliométricas. (BROADUS, 1987).

Tal constatação é reforçada pelo fato de que existem bases de dados bibliográficas que cobrem com precisão e exclusividade a informação tipo científica e técnica (publicações científicas e de patentes). Neste sentido, a hipótese que se sustenta é que:

publicações científicas e de patentes constituem-se fontes de informações e assumem papel destacado e inconteste

\footnotetext{
${ }^{2}$ Scientometrics, revista fundada em 1978 , voltada para publicação de estudos, pesquisa no âmbito da produção científifica.
}

como indicadores de produção de conhecimentos certificados no domínio das ciências e das técnicas (XAVIER, 1995).

Da mesma forma, aceitando-se os dois (2) postulados abaixo enunciados, implícitos em todos os métodos de análise bibliométrica, explicita-se que: "os estudos das publicações científicas permitem vincular os conhecimentos $e$ suas estruturas segundo às escolas de pensamento e suas evoluções" e que, portanto, do ponto de vista da prática, reforça-se a idéia, já anteriormente explicitada de que, em síntese, a cientometria é um reducionismo bibliométrico (PRICE, 1963).

- primeiro postulado: uma obra científica é o produto objetivo da atividade intelectual criativa. Num contexto científico, uma publicação é uma representação da atividade de pesquisa de seu autor. O maior esforço deste autor é de persuadir os pares de que suas descobertas, seus métodos e técnicas são particularmente pertinentes. $\mathrm{O}$ modo de comunicação escrita fornecerá, portanto, todos os elementos técnicos, conceituais, sociais e 
econômicos que o autor busca afirmar ao longo de sua argumentação;

- segundo postulado: a atividade de publicação científica é uma eterna confrontação entre as reflexões intrínsecas do autor e os conhecimentos que ele adquiriu pela leitura dos trabalhos originários dos outros autores. Desta forma, a publicação é o resultado de uma comunicação entre a razão individual e a coletiva. Assim, os pesquisadores, para consolidar suas argumentações, fazem referência aos trabalhos dos outros pesquisadores que, constituem, com esse arranjo, um certo consenso na comunidade científica. Deste fenômeno, pode-se dizer que: existe uma relação entre todos os trabalhos científicos publicados, não sendo possível, no entanto, precisar o tipo de relação: se direta ou indireta, reconhecida ou dissimulada, consciente ou inconsciente, acordada ou não.

Estes postulados, que foram inicialmente definidos para fins da pesquisa científica, foram, em seguida, admitidos como válidos para as publicações reunindo conhecimentos técnicos ou tecnológicos: as patentes. Apoiando-se sobre estes dois postulados, o princípio da bibliometria é de analisar a atividade científica ou técnica através de estudos quantitativos das publicações. Os dados quantitativos são calculados a partir de contagens estatísticas das publicações ou de elementos extraídos das mesmas. Desta forma, pode-se dizer que, a bibliometria é um termo genérico, que reúne uma série de técnicas estatísticas buscando quantificar os processos da comunicação escrita (ROSTAING, 1996).

Ao introduzir o termo bibliometria, Pritchard pretendeu substituir a expressão "bibliografia estatística" que vinha sendo empregada desde 1923, data em que Hulme, (1923) apresentou o seu trabalho. Pritchard argumentava que "bibliografia estatística" poderia dar margem a interpretações distorcidas como, por exemplo, dar a entender tratar-se de uma bibliografia a respeito de estatística (PRITCHARD, 1969).

Devido ao fato de que, a definição proposta por Pritchard não dava nenhuma 
indicação da finalidade da bibliometria e, das aplicações bibliométricas haverem sido, por longo tempo, fortemente atreladas ao domínio da gestão de bibliotecas e de centros de documentação, certamente pela ênfase econométrica que sugeria, estudos bibliométricos sobre circulação das publicações, que ultrapassavam fronteiras eminentemente biblioteconométricas, não chegavam a ser destacados com a mesma importância destes.

Foi, para distinguir estes dois tipos de aplicação, que apareceu o termo "cientometria". Numa conferência, Broadus estabeleceu esta distinção...

Então que a bibliometria teria por objeto estudar os livros ou as revistas científicas e por objetivo compreender as atividades de comunicação da informação, a cientometria teria por objeto estudar aspectos quantitativos da criação, difusão e utilização da informação científica e técnica e por objetivo a compreensão dos mecanismos de pesquisa como atividade social (BROADUS, 1987).

Assim, a bibliometria reagruparia o conjunto dos métodos para ajudar a gestão da biblioteca e a cientometria pesquisaria as leis que regem à ciência, daí sua denominação "Ciência da Ciência" por Solla Price (ROSTAING, 1996).

Faz-se necessário observar-se ainda que os estudos quantitativos da ciência e da tecnologia comportam uma abordagem de pesquisa aplicada e uma outra de pesquisa fundamental. A primeira obedece preponderantemente à demanda por indicadores quantitativos de ciência e da tecnologia da parte dos gestores de política científica, pública ou privada. Quanto ao segundo, considera-se que os métodos quantitativos e principalmente a análise de dados constituem um elemento indispensável para fazer avançar a nossa compreensão sobre os estudos da ciência como um sistema complexo de produção e de troca de conhecimentos (VAN RAAN, 1988).

\subsection{Os indicadores: especificidades e construção}

$\mathrm{Na}$ atividade de pesquisa, as medidas e os números são utilizados para analisar os dados a fim de aperfeiçoar a qualidade dos seus estudos (RAVICHANDRA RAO, 1986). No termo cientometria, o sufixo "metria" dá margem tanto ao 
sentido de métrica como de medida. Em relatório encomendado para a SGDN3, Dutheiul faz distinção entre esses dois sentidos:

A métrica aplica-se a um conjunto para o qual aceita-se uma convenção, permitindo definir as 'distâncias' entre os elementos, o que se constitui em classificar por semelhança ou dessemelhança. A medida é a avaliação de uma grandeza criada a partir de sua relação com uma outra grandeza de mesma espécie adotada para unidade e como comparação (DUTHEIUL, 1991).

Os métodos cientométricos situam-se entre estes dois sentidos. O conceito de medida está bem representado pelos estudos cientométricos utilizando indicadores univariáveis4, em que cada elemento em estudo é medido segundo uma dimensão escolhida. (ROSTAING, 1996).

Por outro lado, o conceito de métrica é mais apropriado para indicadores relacionais. Neste caso, as comparações entre os elementos bibliográficos não são estabelecidos a partir de referenciais a

\footnotetext{
${ }^{3}$ Secrétariat General de la Défense Nationale França

${ }^{4}$ Indicadores univariáveis: medida puramente quantitativa, baseada na simples contagem ou no cálculo de coeficientes entre diferentes elementos bibliográficos.
}

uma só dimensão, mas a partir de fatores influentes. Os métodos empregados buscam representar os elementos segundo cálculos de "distância" que deverão estimar graus de "semelhança" ou de "dessemelhança" entre os elementos. Exemplo marcante, neste sentido, é o caso do método de análise de co-citação5 (CALLON, COURTIAL, PENAN, 1993).

A cientometria é, portanto, um dispositivo de medida, baseado em técnicas estatísticas, que tem por objetivo identificar e tratar as informações contidas nas publicações científicas e técnicas, disponíveis nos sistemas de informação, essencialmente, referências bibliográficas de artigos, de livros e de patentes; razão pela qual torna-se importante analisar o papel destas diferentes publicações nas atividades dos pesquisadores, engenheiros...

Para uma explicitação mais do ponto de vista pedagógico, sobre a análise do papel destas publicações para os fins propostos neste trabalho - indicadores de produção científica -, optou-se pela utilização de 
uma abordagem do "Centre de Sociologie de Innovation"6, fundada no princípio de que a pesquisa é uma atividade cuja natureza e resultados podem ser analisados e avaliados segundo 5 (cinco) dimensões principais, constituindo o que eles vieram a denominar de "a rosa dos ventos" da pesquisa, Figura 1, (CALLON, COURTIAL, PENAN, 1993):

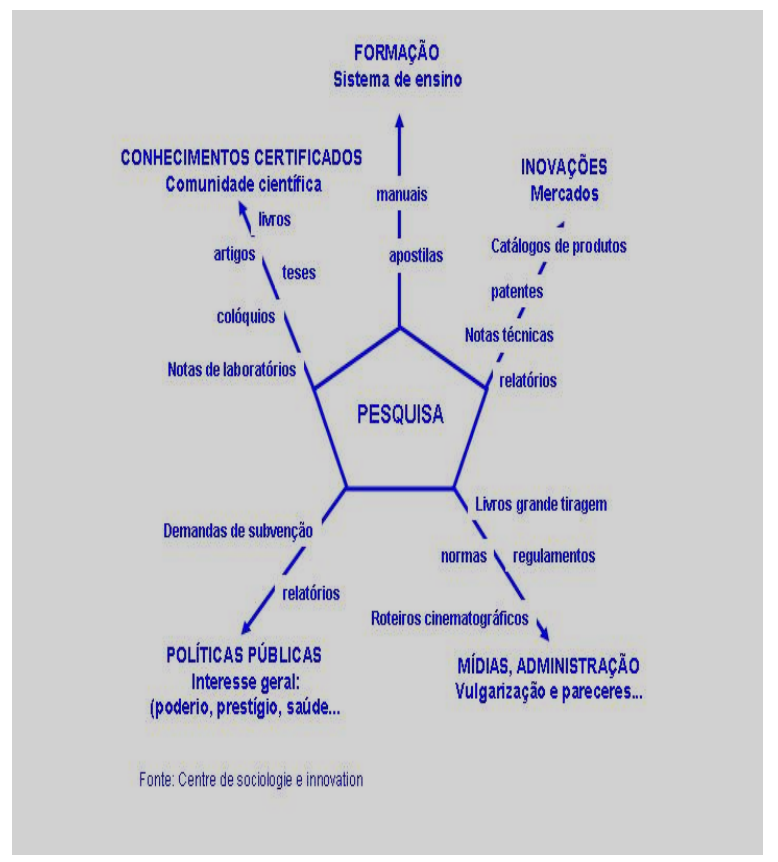

Figura 1:A rosa dos ventos da pesquisa.

\footnotetext{
${ }^{5}$ aparição simultânea de duas citações, formando um par que se repete em um grande número de publicações.

60 "Centre de sociologie e innovation" é um laboratório da

"École dês Mines de Paris". Seus trabalhos são consagrados à

Sociologia das Ciências e das Técnicas, bem como, à Sócioeconomia da Inovação. É um dos raros centros de pesquisa da França tendo desenvolvido métodos científicos originais.
}

i. a pesquisa contribui para a produção de conhecimentos cuja qualidade e interesse são avaliados pela comunidade científica, razão pela qual, diz-se que estes conhecimentos são "certificados".

A comunidade científica coloca os pesquisadores em estado de concorrência. A competição estimula a produção de conhecimentos. Como conseqüência da competição, os conhecimentos gerados precisam ser atestados: somente sobrevivem e se expandem os resultados que resistem à crítica coletiva: "índice de citação e co-citação". Esta pesquisa é geralmente qualificada de "acadêmica".

ii. a pesquisa pode dar origem a um processo de valorização econômica, que conduz a geração de inovações, ou seja, à comercialização de novos produtos e procedimentos;

As inovações inscrevem-se nas estratégias das empresas para criar o que os economistas nomeiam de "vantagens competitivas", indicador que fixa a superioridade de uma organização face 
aos concorrentes. Neste caso, a pesquisa obedece à lógica da competição econômica e a avaliação repousa sobre a contribuição que a pesquisa proporciona à atividade industrial.

iii. a pesquisa pode ser igualmente mobilizada para contribuir para ações de "interesse geral".

Algumas pesquisas de interesse público tomam a forma de programa, tendo como objetivo realizar objetos técnicos complexos como, por exemplo, um avião de combate, um satélite meteorológico ou um programa nuclear para fins de geração de energia. Em outros casos, a finalidade dos programas é mais difusa: pesquisadores e tecnólogos estabelecem investigações epidemiológicas; inspecionam a camada de ozônio em busca de buracos; realizam investigações sobre espécies animais ameaçadas de extinção.

No caso de programa voltado para objetivos de interesse geral, a pesquisa é colocada sobre a tutela de uma agência ou de organismos públicos. Neste caso, o mecanismo de regulação não é, nem indicadores de acumulação de conhecimentos em si, nem a geração de uma vantagem competitiva e sim algo de mais qualitativo (poderio, prestigio, bemestar social) materializado através do julgamento político e do debate público que suscita.

iv. a contribuição às atividades de formação constitui para a pesquisa um espaço de aplicação essencial.

Os conhecimentos e as práticas elaborados pelos pesquisadores são, dessa maneira, transformados em competências incorporadas nos indivíduos (estudantes, participantes de cursos profissionalizantes) que, na seqüência os colocam em prática nos diferentes setores de atividade: indústria, serviços públicos, ensino, pesquisa. A sistematização dos conhecimentos, a sua organização, com vistas a sua transmissão, obedecem a lógicas estreitamente dependente da maneira como as instituições de formação praticam a concorrência entre elas e das suas relações de práticas comerciais com o mercado.

$\begin{array}{llllr}\text { v. a pesquisa } & \text { não } & \text { pode } & \text { se } \\ \text { desenvolver } & \text { junta } & \text { a } & \text { uma }\end{array}$


sociedade hostil à ciência e ao progresso técnico.

Pesquisadores e tecnólogos sempre se esforçaram para apresentar suas atividades de forma a despertar interesse para um público dito não iniciado, seja satisfazendo sua curiosidade, seja fazendo-o interessar-se por certos resultados esperados ou desejados.

A forma utilizada para esta ação é múltipla: publicações de obras ou de realizações de emissões de vulgarização; campanhas de mobilização da opinião para apoiar pesquisas sobre problemas maiores - proteção ao meio ambiente, combate à dengue, combate à fome: Ação da Cidadania Contra Fome e a Miséria e pela Vida, do Betinho.

Quando cientistas, pesquisadores engajam-se em debates sobre o reaquecimento da atmosfera, ou sobre o desaparecimento da camada de ozônio, estão, de uma forma ou de outra, registrando os conhecimentos que eles produziram, num espaço público, num fórum de debate com outros setores. Da mesma forma, quando eles contribuem para a elaboração de normas de segurança para centrais nucleares ou, na redação para a proteção do meio ambiente ou, na negociação de cotas de pescas em zonas costeiras, eles intervêm na condição de especialistas para fazer valer o ponto de vista da ciência ou da técnica.

Nestas situações, o pesquisador é um especialista entre outros, e seu ponto de vista, em geral, determinante, não será o único a ser considerado. Em síntese, isto quer dizer que: quando autoridades participam de iniciativas de vulgarização e de emissão de pareceres, os pesquisadores submetem-se a formas específicas de avaliação e de gratificação: o impacto de uma obra de vulgarização mede-se em número de exemplares vendidos; o sucesso de uma campanha de pesquisa contra o câncer, por exemplo, é função do volume de fundos arrecadados; um parecer emitido por um pesquisador, traduz-se por opiniões ou recomendações que vierem a ser ou não, acolhidas nas decisões finais.

Por fim, qualquer que seja a dimensão, na qual os pesquisadores estão engajados, ela somente se materializa na produção de documentos escritos. Quando pesquisadores elaboram pesquisas, eles 
produzem artigos; quando participam de processo de inovação, depositam patentes ou divulgam notas técnicas ou manuais de utilização; quando se envolvem com a docência, dirigem tese, elaboram manuais, apostilas; quando participam de programas públicos, redigem projetos para obter subvenções e relatórios justificando a utilização dos recursos e, como mencionado anteriormente, se se consagram a popularização, elaboram livros, roteiros, contribuem para a redação de regulamentos, de pareceres.... Considerado nas cinco dimensões expostas, a pesquisa é uma vasta empresa de escritura: ela prolifera documentos de todos os tipos, Figura 1, (CALLON, COURTIAL, PENAN, 1993).

\section{CONCLUSÃO}

"Somente se conhece bem um fenômeno quando é possivel expressá-lo em número".

Lord Kelvin

Diferentemente da definição de bibliometria proposta por Pritchard, muito geral, que não indicava uma finalidade, a cientometria, embora se caracterize fundamentalmente, como um reducionismo bibliométrico, surge, no entanto no contexto de uma proposta de seu idealizador, Solla Price, de constituir- se como um arcabouço teórico da disciplina "Ciência da Ciência".

A razão para este fato tem relação direta com os desafios sócio-econômicos da era moderna, caracterizada essencialmente, pela reconhecida e certificada importância que a ciência assume junto à sociedade.

Atividade complexa e de alto risco, envolvendo investimentos financeiros vultuosos e de longo prazo, com resultados de natureza sempre intangíveis e, em geral, através de representações pouco acessíveis aos não iniciados, a gestão da atividade de pesquisa exige não só o desenvolvimento e a formulação de métodos e técnicas para quantificar os seus resultados, mas também, e principalmente a formação de grupos de pesquisa para compreender os fenômenos da criação do conhecimento e transformálos em resultado econômicos, através das 5 (cinco) dimensões de impacto da pesquisa aqui relatadas; para identificar e estruturar os dados a serem apurados, como também para entendê-los e interpretá-los. 
Estruturada, na concepção de Solla Price, com o propósito acima, a "Ciência da Ciência", embora seja hoje já considerada uma disciplina de idade adulta, com um crescimento espetacular, em razão de haver mantido sua unidade, seu foco central, sem se dispersar em tendências, apesar da diversidade de suas orientações e aplicações, constata-se, pelo que ficou exposto neste trabalho, que não há, por parte dos profissionais atuando na área, concordância com respeito aos conceitos e terminologias utilizados.

Acresce-se a isto o fato de que, os repertórios dos acervos científicos consagrados, como no caso do ISI, não haverem sido criados para medir a performance dos pesquisadores, das equipes ou dos laboratórios. Esses repertórios permitem essencialmente que se estabeleçam as relações que existem entre os diversos trabalhos de pesquisa, realizados em nível mundial. Há assim um desvirtuamento e, conseqüentemente, é extremamente perigoso utilizar dados que foram inicialmente, concebidos para estudos de análise global e qualitativas, utilizá-los para fins de tomada de decisão pelos gestores públicos.
Consciente do nível de complexidade e, de que há ainda muito a ser feito principalmente no nível de infra-estrutura para produzir os resultados esperados, todas as agências nacionais de expressão, que se preocupam e promovem estudos de avaliação da produção científica para fins de elaboração de política pública de pesquisa, vêm estimulando a constituição de fontes de dados, a formação de pesquisadores na área, o desenvolvimento e formulação de indicadores e métodos específicos e apropriados aos seus interesses.

É neste contexto, que se inclui o Scielo, a plataforma Lattes, iniciativas das agências de incentivo e financiamento da pesquisa de nosso país. De forma modesta, incluise também a iniciativa de nosso projeto de pesquisa, ainda numa fase embrionária, que se propõe nuclear discussões, liderar grupo de pesquisa na área e formar recursos humanos aptos ao desenvolvimento de indicadores, de projetos de fontes de informação, de análise e interpretação de resultados, subsidiar agências de financiamento público de pesquisa e seus gestores. 


\section{REFERÊNCIAS}

BROADUS, R.N., "Toward a Definition of « Bibliometrics ». Scientometrics, v. 12, n. 6, p. 373-379, 1987.

BROOKES, B. C. Comments on the scope of bibliometrics. In: L. EGGHE and R. Rousseau (eds), Informetrics 87/8: Select Proceedings of the First International Conference on Bibliometrics $d$ theoretical aspects of information retrieval,Amsterdam: Elsevier, 1987. p.29-41.

CALLON, M.; COURTIAL, J-P.; PENAN, H. La scientométrie. Paris: Presses Universitaires de France, 1993. 126p. ("Que sais-je?", n. 2727).

DOBOROV, G., M.; KORENNOI, A., A. The information basis of scientometrics. In: On Theoretical Problems of Informatics, Moscou, VINITI for FID, 1969, p.165-191.

DUTHEUIL, C. L'état de l'art de la bibliométrie et de la scientométrie en France et à l'étranger, Rapport pour le compte du SGDN, n.

24/SGDN/STS/VST/5, 1991, 64p.

HULME, E. W. Statistical bibliography in relation to the growth of modern civilization, London: Edition Grafton, 1923. 44p.

MEADOWS, A. J. "Theory in information science". Journal of Information Science, v. 16, n. 1, p. 59-63, 1990.

PRICE D. J. de S. "The Structures of Publication in Science and Technology", dans H. Gruber et D.G. Marquis (éds.), Factors in the Transfer of Technology.
Cambridge, Mass.: The MIT Press, p. 91104, 1969.

. Little Science, Big Science.

New York: Columbia University Press, 1963. 118p.

PRITCHARD, A. "Statistical

Bibliography or Bibliometrics?". Journal

of Documentation, v. 25, n. 4, p. 348-349, Dec. 1969.

QUONIAM, L. Bibliométrie sur des références bibliographiques:

méthodologie. In : DESVALS, H.; DOU, H. (Org.) La veille technologique: l'information scientifique, technique et industrielle. Paris: Dunod, 1992. p. 243262.

RAVICHANDRA RAO, I. K. Métodos quantitativos em biblioteconomia e ciência da informação. Brasília:

Associação dos Bibliotecários do Distrito Federal. Washington, DC: Organização dos Estados Americanos, 1986. 269p.

ROSTAING, H. La bibliométrie et ses techniques. Tolouse : Ed. Sciences de la Société, 1996. 131p.

ROUSEAU-HANS, F.; THIL, J. Veille et informatique: des besoins aux solutions. Technologies Internationales, Strasbourg, n. 39, p. 33-36, nov. 1997.

VAN RAAN, A. F. J. (ed.). Handbook of Quantitative Studies of Science and Technology. Amsterdam: North Holland, Elsevir Science Publishers, 1988.

XAVIER, P. Aux sources de la scientométrie. Dossier Solaris, n. 2, Bibliométrie, Scientométrie, Infométrie. Disponível em :

$<$ http://www.info.unicaen.fr/bnum/jelec/S olaris/d02/2polanco1.html $>$. Acessado em 16 jan. 2003. 
Raimundo Nonato Macedo dos Santos

Prof. Dr. do Curso de Pós-Graduação em Ciência da Informação da PUC-Campinas

rnmacedo@uol.com.br

Artigo aceito para publicação em:

30 maio 2003 